\title{
Las comunidades indígenas de la Nueva España y el movimiento insurgente (1810-1817)
}

\author{
Manuel Ferrer Muñoz \\ Instituto de Investigaciones Jurídicas \\ Universidad Nacional Autónoma de México, México D. F.
}

Se analiza el papel desempeñado por las comunidades indígenas de la Nueva España en la critica coyuntura del conflicto insurgente que se desencadenó en 1810. El estudio profundiza en las motivaciones que indujeron a esas comunidades a tomar uno u otro partido de los enfrentados en los campos de batalla, y pone el énfasis en las divisiones que imperaron en su seno. Se muestra, en fin, el papel subordinado de los indios sublevados, que nunca gozaron de la plena confianza de sus dirigentes criollos.

Al comenzar estas líneas me viene a la mente la brutal expresión empleada por Francisco Bulnes para significar el lugar reservado a los indios por los artífices de la política mexicana a lo largo del siglo XIX: "una máquina de carne para morir o matar por cualquiera causa o sin causa". ${ }^{1}$ Tiempo habrá, más adelante, para volver sobre esta consideración. De momento, esa desagradable imagen nos despeja el camino para acercarnos al tema que nos hemos propuesto desentrañar, en la medida en que esto sea posible: ¿será cierto, como quizá sospechamos, que la condición de "acarreados" acompañó también a los indios que murieron en los campos de batalla a raíz de la agitación revolucionaria desatada en 1810 ?

Tal vez sea Eric Van Young uno de los historiadores que más ha insistido en la importancia que debe atribuirse a las conspiraciones que precedieron al estallido de la insurrección de septiembre de 1810 - tanto las apócrifas como las reales-, para comprender el comportamiento de los pueblos indígenas durante la guerra insurgente. ${ }^{2}$ También nosotros arrancaremos, como punto de partida, de dos sucesos aparentemente desconectados del trascendental movimiento iniciado en aquel año por el cura Hidalgo. Al lector impaciente debemos advertir que no estamos proponiendo una introducción ajena al objeto de nuestro estudio. El saldo de uno y otro episodio es elocuente: sin un estímulo exterior, y sin un liderazgo también ajeno, los pueblos indígenas que habitaban lo que pronto sería la República mexicana se hallaban incapacitados para una acción de amplio

\footnotetext{
1 Bulnes, Francisco: El verdadero Díaz y la Revolución, México, 1992, págs. 14 y 50.

2 Van Young, Eric: La crisis del orden colonial. Estructura agraria y rebeliones populares de la Nueva España, 1750-1821, México, 1992, pág. 344.
} 
calado. Para explicar esa impotencia no es preciso acudir al socorrido tópico de la ignorancia indígena ${ }^{3}$ — como cualquier otro lugar común, poseedor de cierta dosis de verdad-: basta pensar en la completa falta de articulación de las comunidades indígenas, fragmentadas, divididas y enfrentadas muchas veces entre sí, que dejaba vía libre a la acción de los inconformes criollos.

Ese era el sentir de las autoridades novohispanas, como lo muestra una carta del brigadier Calleja al virrey Venegas, fechada el 29 de enero de 1811, en la que expresaba su temor por el peso que representaba la Nueva España para "una metrópoli que vacila". Tanto criollos como europeos, proseguía Calleja, se hallaban convencidos de las ventajas de un gobierno independiente; y tan generalizado era ese sentimiento que el triunfo de la causa separatista no habría encontrado muchos obstáculos si no hubiera mediado la "absurda insurrección de Hidalgo" que, al abrir las puertas de la rebelión a los indígenas, desvirtuó la naturaleza de aquellas aspiraciones independentistas. ${ }^{4}$

La invertebración entre las comunidades originó comportamientos muy diferenciados de unas y otras, que han de ser tomados en cuenta a la hora de enunciar juicios que pretendan traspasar particularismos. Si William B. Taylor captó una notable diversidad en las formas de inquietud rural que se manifestaron en Jalisco y en Oaxaca a principios del siglo XIX, y en las actitudes observadas por los pueblos de una y otra región durante las luchas insurgentes, ${ }^{5}$ la investigación que hoy presentamos enfatiza la pluralidad de decisiones de los pueblos indígenas en el marco más amplio del Virreinato, y quiere romper con el panorama convencional de una masa aborigen que se batió con entusiasmo por la causa de Hidalgo y de Morelos.

3 Hamill ejemplifica la ignorancia de los indígenas con el "descubrimiento" que hicieron, después de haber dado muerte en Guanajuato al intendente Riaño: no tenía rabo, a pesar de que la propaganda y los rumores les habían convencido de que todos los oficiales españoles estaban dotados de ese apéndice, por su condición de almas condenadas: Hamill, Jr., Hugh M.: The Hidalgo Revolt. Prelude to Mexican Independence, Westport, Connecticut, 1981, pág. 137.

4 Annino, Antonio: "Prácticas criollas y liberalismo en la crisis del espacio urbano colonial. El 29 de noviembre de 1812 en la ciudad de México“, Secuencia: Revista de Historia y Ciencias Sociales, nueva época, núm. 24, México, D. F., septiembre-diciembre, 1992, págs. 121-158 (pág. 124). El mismo artículo ha sido incluido en Montalvo Ortega, Enrique (coord.): El águila bifronte. Poder y liberalismo en México, México, 1995, págs. 17-63.

5 Taylor, William B.: "Bandolerismo e insurrección: agitación rural en el centro de Jalisco, 1790-1816”, en Katz, Friedrich (comp.), Revuelta, rebelión y revolución. La lucha rural en México del siglo XVI al siglo XX, 2 vols., México, 1990, vol. I, págs. 187-222 (págs. 187 y 207). 


\section{Las primeras señales de alarma}

Diez años antes del estallido de la guerra insurgente se produjo en Tepic, Nueva Galicia, un brote de revuelta derivado de móviles que nunca llegaron a ser conocidos con detalle. No obstante, las noticias sobre esas ocurrencias circularon por toda la Nueva España y dejaron a su paso temores y esperanzas: "en cierto tiempo se divulgó que en tierra adentro había un rey coronado, el señor Mariano I, y sólo con haberse dicho ya, esta vil, infame y traidora nación española no hallaba medio o ardid para recoger sus caudales, e irse a sus tierras". ${ }^{6}$

Existen muy interesantes coincidencias entre ese episodio y el que tuvo como protagonista a José Bernardo Herrada — el mesías trastornado de Durango - a fines de 1800 y principios de 1801: tantas que algunos funcionarios de la administración virreinal llegaron a pensar que Herrada y Mariano eran una misma persona. ${ }^{7}$ Eric Van Young y Enrique Florescano se han ocupado de esos sucesos y Van Young ha señalado dónde se halla la correspondiente documentación de archivo. ${ }^{8}$ Remitimos, en fin, a la Historia de Méjico de Lucas Alamán, que proporciona otras referencias. ${ }^{9}$ Los acontecimientos de Tepic, cuyo relato omitimos por las razones apuntadas, revelan aspectos de interés y muestran, en último término, la incapacidad en que se hallaban los indígenas para articular con visos de éxito un movimiento de resistencia al poder virreinal.

También en el Archivo General de Indias hemos localizado otro interesante expediente, relacionado éste con la causa que se instruyó en septiembre de 1808 - Garibay había reemplazado ya a Iturrigaray - a dos españoles: José Luis Rodríguez de Alconedo, patrón de platería, y su her-

6 Carta de José Alejandro Molina y Manuel de la Trinidad Fernández a Morelos, sin fecha, en Prontuario de los insurgentes, introducción y notas de Virginia Guedea, México, 1995, págs. 78-79.

7 Van Young, Eric: La crisis del orden colonial, págs. 365-386; Van Young, Eric: "Millennium on the Northern Marches: The Mad Messiah of Durango and Popular Rebellion in Mexico, 1800-1815", Comparative Studies in Society and History, vol. 28, 1986, págs. 385-413; Van Young, Eric: "Quetzalcóatl, King Ferdinand, and Ignacio Allende Go to Seashore; or Messianism and Mystical Kingship in Mexico, 1800-1821", en Rodríguez O., Jaime E. (ed.): The Independence of Mexico ant the Creation of the Nation, Los Angeles-Irvine, 1994, págs. 109-127 (págs. 109-110), y Florescano, Enrique: Memoria mexicana, México, 1995, págs. 492-496.

8 Van Young, Eric: La crisis del orden colonial, págs. 399-400, y Florescano, Enrique: Memoria mexicana, págs. 496-500. Personalmente he consultado este expediente en el Archivo General de Indias (en adelante, AGI), Estado, 29, núm. 7, y Estado, 30, núm. 19

9 Alamán, Lucas: Historia de Méjico. Desde los primeros movimientos que prepararon su independencia en el año de 1808 hasta la época presente, 5 vols., México, 1942, vol. I, págs. 132-134. 
mano, José Ignacio, profesor de farmacia y administrador de una botica, a los que se acusaba de intrigar para promover una insurreción en México. ${ }^{10}$

Según confesión del segundo de los presuntos cómplices, cuando fue invitado a sumarse a la conspiración que se hallaba en marcha, los conjurados "tenian ya listados como diez mil Indios, y como quatro mil Americanos", y esperaban la incorporación de otros tres pueblos de indios. Otro de los interrogatorios — aplicado a un mestizo de nombre Espinosaaportó novedades sobre los móviles que impulsaron el complot: "quitarles el mando á los Gachupines, con lo que se haria este Reyno feliz bolviendo á sus dueños que eran los Criollos". ${ }^{11}$

Con independencia de la fiabilidad de esos testimonios - escasamente creíbles en su literalidad-, las averiguaciones judiciales practicadas arrojan luz sobre varios aspectos importantes: son españoles y mestizos quienes se ven implicados como artífices de los preparativos insurreccionales, que persiguen el objetivo inequívoco de operar una traslación del poder político en beneficio de los criollos; y se recurre a los indios como carne de cañón que ni siquiera merece la connotación de "americana": los verdaderos "americanos", a quienes se ha de restituir lo que les pertenecía en calidad de dueños, son los criollos.

Años después, el Ilustrador Americano dejó traslucir las mismas convicciones cuando, al comentar las exageraciones con que la propaganda realista había celebrado el sitio de Cuautla, sostuvo que las armas de Calleja habían triunfado "solamente de las viejas, de los muchachos y de unos pocos indios". ${ }^{12}$

\section{Indiferentismo indígena y revolución liberal gaditana}

Lo expuesto hasta aquí y lo que se desarrollará a continuación proporciona un presupuesto que juzgamos de la máxima importancia para comprender la posición de los indígenas ante la insurgencia. Y es que el estado espiritual y cultural de esas gentes en vísperas de la revolución distaba mucho de ser el óptimo y el deseable. Así lo había reconocido con desaliento el conde de Revillagigedo, años atrás, al comprobar que los

10 AGI, México, 1.472.

11 Ídem.

12 Plan del Ilustrador Americano, en García Díaz, Tarsicio: "La prensa insurgente", en Hernández, Octavio (ed.): La República Federal Mexicana. Gestación y nacimiento, 8 vols., México, 1976, vol. V, t. I, pág. 221. 
esfuerzos empleados para inculcarles la fe y la doctrina "no habían producido el efecto que debía esperarse y los indios estaban aún bien ignorantes y muy rudos en asuntos de religión". ${ }^{13}$

Prácticamente idéntico al panorama trazado por Revillagigedo era el balance realizado por Fernández de Lizardi en uno de sus escritos, dedicado a la dispensa concedida a los indios para que no les obligara el precepto de oír misa algunos días de fiesta, por gozar de la consideración de cristianos nuevos a los que no convenía plantear exigencias demasiado severas:

ahora bien, si esto es así, han pasado ya los trescientos años de neofitazgo, ¿deben o no reputarse los indios como cristianos viejos? Si deben reputarse como tales, es fuerza que les obliguen los preceptos de la Iglesia como todos. Si no, ¿hasta cuántos siglos han de ser los indios aprendices de cristianos? ¿Si será hasta el fin del último, usque ad consumationem saeculi? $?^{14}$

Por tales motivos y por todo un cúmulo de razones que no es oportuno analizar aquí, el arranque del proceso insurgente sorprendió al indio en un status de tremenda inferioridad: no sólo en su condición socioeconómica, sino también - y sobre todo- en sus niveles educativos y culturales. Es, pues, comprensible que la trasformación del orden político acometida por las Cortes gaditanas difícilmente podía arrancar al indio de su apatía y abulia habituales.

Encontramos un buen exponente del alejamiento entre los dirigentes políticos del virreinato y el grueso de la población india en una divertida e imaginaria carta de los indígenas de Tontonapeque a El Pensador Mexicano, a la que dieron pie las pláticas del cura sobre las consecuencias del principio de igualdad contemplado en la Constitución de Cádiz, ya enunciado antes con carácter general en el decreto de 15 de octubre de 1810 y, para el caso de los indios, en el de 9 de febrero de 1811.

En la escéptica apreciación de los naturales del pueblo, su condición de ciudadanos ${ }^{15}$ sólo se había materializado en el incremento de la carga impositiva.

13 Zahino Peñafort, Luisa: Iglesia y sociedad en México, 1765-1800. Tradición, reforma y reacciones, México, 1996, pág. 79.

14 Fernández de Lizardi, José Joaquín: "Calendario histórico y pronóstico político. Por el Pensador Mexicano. Para el año bisiesto de 1824” (México, 1823), en Fernández de Lizardi, José Joaquín: Obras, México, 1963-1995, vol. XII, págs. 547-611 (pág. 554).

15 Debemos a Antonio Annino unas reflexiones muy interesantes acerca de lo que él llama "el desliz de la ciudadanía", provocado por la modificación que este concepto experimentó en México por obra del "protagonismo de los pueblos": Annino, Antonio: "Nuevas perspectivas para una vieja pregunta”, en VV. AA.: El primer liberalismo mexicano, 1808-1855, México, 1995, págs. 43-91 (págs. 52-62). 
¿Qué nos importa que nos quiten el dichoso triboto, si nos han cargado de contribociones al antojo del Comandante que ya nos saca el sangre, porque no tenemos mas que darle? Mas mejor lo estabamos antes; y no agora con el maldita Costitucion, que sos mercedes llaman el código á gusto, el código divino y quen sabe que mas. Con razon mochisimos no quieren el Costitocion, y esto que son ricos; pos nosotros los probes indios ¿como los estaremos con esta maldá? ${ }^{16}$

No cabe duda de que Fernández de Lizardi, buen conocedor de su entorno, atinaba al interpretar los incrédulos sentimientos que albergaban los indígenas con relación a las idílicas promesas liberales: y eso no obstante el gran esfuerzo propagandístico desplegado por los patrocinadores del Nuevo Régimen. En efecto, después de que la sublevación de Riego hubiera obtenido el retorno del constitucionalismo a España, se editaron múltiples folletos a través de los cuales se pretendía convencer a los indios de las excelencias del sistema constitucional, con un particular énfasis en su acceso a la condición de ciudadanos, en igualdad de derechos con los demás españoles, y en la supresión de antiguos usos, como la pena de azotes, las mitas o los servicios personales. La apología de las nuevas libertades llegaba al extremo de atribuirles la capacidad de influir en la conciencia de los indios para enseñarles a discernir el bien y el mal:

tantos bienes vais á disfrutar, que no sabreis apreciarlos sino gozandolos realmente, porque sujetos en los tiempos pasados á tantas trabas, opresiones y desdichas, ni conociais el nombre del bien, y el mal mismo se os presentaba en la copa de oro, esto es, con la máscara de bien, con el nombre de proteccion, de amparo, de favor; y embriagados con una lisonjera esperanza, con una falsa seguridad, vuestra alma sensible, connaturalizada con las penas, aletargada con el peso de sus desgracias, á penas como en un profundo sueño, sentia lo gravoso de su suerte miserable. ${ }^{17}$

A la vez, se insistía en la necesidad de que los indios accedieran a la instrucción, como el medio más eficaz para evitar que rebrotaran los antiguos abusos:

vuestro continuo trabajo no os deja lugar para pensar que sois racionales. Mas apartaos un rato de este trabajo; id á las escuelas; instruios en vuestra religion y en vuestros derechos; mandad á vuestros hijos, para que no corran la misma suerte que vosotros: que aprendan á leer, para que así sepan el gran bien que poseen en la sábia Constitucion, y puedan reclamar su observancia siempre que sea necesario. Si en

16 Carta de los indios de Tontonapeque al Pensador Mexicano, s. c., 20 de diciembre de 1820, México, Biblioteca Nacional, Fondo José María Lafragua —en adelante, LAF- 105.

17 Consuelo a los indios, y aliento a los ciudadanos. México, 1820 (LAF 144). 
alguno de vuestros pueblos no hubiere escuelas, exigid á vuestros curas y ayuntamientos que os las pongan, que así lo manda la Constitucion. ${ }^{18}$

Sabemos, sin embargo, que las nobles intenciones que habían inspirado los decretos de Cortes que pretendían suprimir privilegios e igualar a todos ante la ley se vieron frustradas, en buena parte, por la confluencia de una larga serie de factores: muy en particular, las nuevas contribuciones que vinieron a recaer sobre los indios, y las arbitrariedades de los mandos militares, que agravaron la penuria económica de los indígenas. No cabe olvidar, en último término, la discriminación de los americanos que introdujeron las Cortes cuando se ocuparon del delicado asunto de la representación indiana en el órgano legislativo. ${ }^{19}$

En pleno apogeo de la guerra insurgente, cuando apenas había entrado en vigor la Constitución en tierras de la Nueva España, se escribió con amarga ironía en Sud acerca del silencio impuesto a los indios, incapaces de protestar contra los agravios que se les inferían, porque "no nos dexan hablar ni aprender lo necesario"; privados de gustar las uvas de Zapotitlan, pues "decian que por Leyes de Indias solo podian comerlas los Sres. gachupines", y reducidos a la miseria, "porque dixeron los padres que andaban con Hernan Cortes, que los indios habian profesado la pobreza evangelica para salvarse" ${ }^{20}$

\section{Las comunidades indígenas y la coyuntura bélica: ¿insurgentes o realistas?}

Muchas comunidades indígenas pelearon en la guerra insurgente de 1810, sin que pueda sostenerse una adscripción en bloque a uno u otro de los bandos enfrentados. Más aún, como ha hecho notar Alicia M. Barabas

18 La Malinche de la Constitución. En los idiomas mejicano y castellano. Segundo papel. México, 1820 (LAF 261).

19 Ferrer Muñoz, Manuel: La Constitución de Cádiz y su aplicación en la Nueva España (Pugna entre Antiguo y Nuevo Régimen en el virreinato, 1810-1821), México, 1993, págs. 204-215. En relación con este punto son muy conocidas las furibundas críticas de fray Servando Teresa de Mier en la Carta de un americano a El Español sobre su número XIX: Teresa de Mier, Servando: Cartas de un americano 1811-1812, México, 1987, págs. 61-138, y Semanario Patriótico Mexicano, núms. 9 a 19, 13 de septiembre de 1812 al 22 de noviembre de 1812, en García Díaz: "La prensa insurgente...", vol. V, t. I, págs. 415-502.

20 Sud. Continuacion del despertador de Michoacan, núm. 51, 25 de enero de 1813, en García, Genaro (dir.): Documentos históricos mexicanos, 6 vols., México, 1910, vol. IV. 
para el espacio geográfico oaxaqueño, los indígenas de pueblos enteros que se vieron involucrados en el conflicto titubearon en la elección del bando que debían apoyar: así, mientras que algunos pueblos de la mixteca de la costa sostuvieron la causa independentista, otros del mismo litoral se pronunciaron en favor de los españoles. ${ }^{21}$ Incluso se podría pensar, con Hamill, que la mayoría de indios y castas de la Nueva España prefirió mantenerse lejos del conflicto, y que sólo se movilizaron cuando éste les afectó de un modo directo. ${ }^{22}$

Virginia Guedea observa, de su parte, que la guerra provocó una participación generalizada de la población de los Llanos de Apan y zonas circunvecinas de Puebla y Veracruz, y que en ambos bandos tomaron parte "tanto gente 'de razón' como la 'indiada". ${ }^{23}$

William B. Taylor afirma que no todos los indios del mundo rural de Jalisco —entonces, Nueva Galicia—, ni siquiera la mayoría, tomaron parte en el levantamiento que tuvo como hitos la batalla de Zacoalco y la ocupación de Guadalajara por las fuerzas de José Antonio Torres; y que, después del retorno de los realistas, los indígenas de Zacoalco quedaron profundamente divididos en sus lealtades políticas y en sus proyectos de futuro. Añade también que el apoyo a la insurgencia no fue una acción colectiva de pueblos enteros - quizá con la excepción del breve período de Torres-, sino decisión de individuos aislados, por numerosos que hubieran podido llegar a ser; e incluso registra la existencia de dos pueblos - Tonalá y Tlajomulco-, que se inhibieron en la lucha que se desarrolló durante aquellos críticos años. ${ }^{24}$

La indeterminación de muchas comunidades indígenas y la identificación de otras muchas con el bando realista pueden ser explicadas de muchos modos. El juicio que expresa Castillo Ledón ayuda eficazmente a pensar esas razones a partir de un fundamento sólido: "la independencia la promovieron los criollos y los mestizos y aun algunos españoles. Hidalgo y todos los jefes pertenecían a las dos primeras clases. La guerra no se

21 Barabas, Alicia M.: "Rebeliones e insurrecciones indígenas en Oaxaca: la trayectoria histórica de la resistencia étnica", en Barabas, Alicia M., y Bartolomé, Miguel A. (coords.): Etnicidad y pluralismo cultural. La dinámica étnica en Oaxaca, México, 1990, págs. 213-256 (pág. 247).

22 Hamill, Jr.: The Hidalgo Revolt..., pág. 48.

23 Guedea, Virginia: La insurgencia en el Departamento del Norte. Los Llanos de Apan y la Sierra de Puebla 1810-1816, México, 1996, págs. 19-20 y 29, y Alamán: Historia de Méjico, vol. II, págs. 385-386. El Diccionario de la lengua castellana, extractado del diccionario enciclopédico, compuesto por Elías Zerolo y otros (París, 1897), definía indiada como "muchedumbre de indios del pueblo, particularmente cuando se amotinan".

24 Taylor: "Bandolerismo e insurrección...”, págs. 198-199 y 213-221. 
declaró precisamente para vengar agravios de los indios; pero sí arrastró a éstos". ${ }^{25}$ Es ésa la interpretación a que se abona Cécile Gouy-Gilbert, que resalta la ambigüedad de la lucha por la independencia que, si bien reunió a los indios bajo la influencia de Hidalgo y de Morelos, "se llevó a cabo sobre todo por el hecho de que los criollos querían desembarazarse de la 'burocracia peninsular' sin cambiar por ello la estructura social de la Colonia". ${ }^{26}$ Dieter George Berninger participa de la misma opinión: "los verdaderos beneficiarios de la independencia fueron los criollos [.... Todos sus objetivos en la lucha por la independencia tenían estrecha relación con el deseo de sustituir al gachupín [... en las posiciones de poder". ${ }^{27}$

A fin de cuentas, el parecer de Castillo Ledón reproduce los puntos de vista expresados por la mayoría de autores del siglo pasado, que admitieron una movilización masiva de indígenas durante la insurrección, que se decidió como por instinto. ${ }^{28}$ Así lo expresó nítidamente Lorenzo de Zavala: "los indios tomaron una parte tan activa en la revolución, cuanta les permitían sus facultades morales y su incapacidad de discurrir por el estado de degradación en que estaban"; "Viva la América y la virgen de Guadalupe, fue el grito dado en el pueblo de Dolores, y diez mil indios mal armados y medio desnudos agrupados alrededor de sus corifeos, obraban por un sentimiento desconocido y corrían a destruir a sus opresores". ${ }^{29}$

El hecho mismo de que muchos campesinos indios se contasen entre los seguidores de Hidalgo indujo a unas cuantas corporaciones de naturales, cuyo régimen de vida estaba ligado a centros urbanos —incluidas las parcialidades de la capital del virreinato ${ }^{30}$ las repúblicas de indios de Guadalajara y el gobernador de naturales de Querétaro-, a manifestar su fidelidad a la causa realista y a proponer la organización de tropas de voluntarios.

25 Castillo Ledón, Luis: Hidalgo. La vida del héroe, 2 vols., México, 1972, vol. II, pág. 272.

26 Gouy-Gilbert, Cécile: Una resistencia india. Los yaquis, México, 1985, pág. 53.

27 Berninger, Dieter George: La inmigración en México (1821-1857), México, 1974, págs. 9-10.

28 Esta explicación me recuerda la tesis de Villoro sobre el "instanteísmo" de la decisión de Hidalgo de embarcarse en la revuelta, refutada en tiempos por Hamill: The Hidalgo Revolt..., pág. 120.

29 Zavala, Lorenzo de: Ensayo histórico de las revoluciones de México desde 1808 hasta 1830, México, 1969, págs. 46 y 291.

30 Lira, Andrés: Comunidades indígenas frente a la ciudad de México. Tenochtitlan y Tlatelolco, sus pueblos y barrios, 1812-1919, México, 1983, págs. 54-55. A Antonio Annino debemos algunas observaciones muy interesantes sobre las peculiaridades del "espacio indio" de la ciudad de México, no enteramente sometido a las parcialidades, como se deduce de la nutrida presencia en la parroquia de la Santa Veracruz de indígenas procedentes de la región occidental del valle de México: Annino: "Prácticas criollas...", págs. 135 y 144. 
Lucas Alamán recoge la respuesta que, unos cuantos meses antes de la sublevación de Hidalgo, había dado el gobernador de la parcialidad de indios de San Juan a la proclama de Garibay, por la que éste informó de la negativa marcha de la guerra que se sostenía en la península ibérica contra las armas de Napoleón: "aun cuando no hubiese en España mas que un pueblo libre de los enemigos, donde residiese aquel cuerpo nacional (la junta central), á este se debe reconocer como lugar teniente de S. M., y no pueden (los indios), tener otro rey que el inmediato sucesor de la casa de Borbón". ${ }^{31}$ $\mathrm{Al}$ mismo autor debemos el registro de las protestas de fidelidad de otras corporaciones de indígenas, después ya de haberse producido la revuelta del cura de Dolores, y la constancia del alborozo con que acogieron las parcialidades capitalinas la noticia del regreso de Fernando VII a suelo español..$^{32}$

Aunque pudiera dudarse de la sinceridad de esas declaraciones, parece verosímil su rectitud si se tiene cuenta - como observa Virginia Guedea- que no existían relaciones entre los diversos grupos indígenas que facilitaran la manipulación de aquellas expresiones de lealtad que, por lo demás, no lograban encubrir signos de simpatía hacia el movimiento insurgente de parte de algunos dirigentes de las parcialidades capitalinas, como los que participaron en unas juntas clandestinas celebradas en el tecpan de Santiago en junio de 1810 con la finalidad de impedir el envío de dinero a España, obtener el consentimiento para que los pueblos pudieran reunirse y tratar sobre la independencia, exigir la instalación de Cortes y reclamar al gobierno la entrega de armas a los indios..$^{33}$

Ese fue también el caso de Francisco Galicia, que había sido gobernador de la parcialidad de San Juan y que, después de haber sido designado elector del ayuntamiento de México en las elecciones de noviembre de 1812 por la parroquia de Santa Cruz Acatlán, escribió a Rayón informándole de lo ocurrido en aquella jornada y prometiéndole ayuda si se acercaba a México con sus fuerzas. ${ }^{34}$ Condenado más tarde por su apoyo a los

31 Alamán: Historia de Méjico, vol. I, págs. 273-274.

32 Ibídem, vol. I, pág. 369, y vol. IV, pág. 144.

33 Guedea, Virginia: "Los indios voluntarios de Fernando VII", Estudios de Historia Moderna y Contemporánea de México, vol. X, México, D. F., 1986, págs. 11-81 (págs. 34-35, 45 y 49), y Guedea, Virginia: En busca de un gobierno alterno: los Guadalupes de México, México, 1992, pág. 41.

34 Alamán: Historia de Méjico, vol. III, págs. 273-274. Rayón respondió el 10 de diciembre: "los movimientos de esa capital son expresivos de su patriotismo. La Junta Suprema está informada de todo; se nos avisará con tiempo para protegerlos con nuestras armas; que no se destruyan los edificios ni se disipen los caudales. Y sólo destronar a Venegas, los oidores y gachupines": Prontuario de los insurgentes, págs. 207 y 208. 
rebeldes, murió en prisión en Acapulco mientras esperaba la embarcación que iba a conducirlo a su destierro en las Islas Marías. ${ }^{35}$

Otro antiguo gobernador de la parcialidad de San Juan, Dionisio Cano Moctezuma, acreditado también como elector en noviembre de 1812 por Santo Tomás, se vio implicado en una averiguación sobre su "conducta y manejo", por considerársele autor de una carta que se encontró en poder de Morelos. Constaba además a las autoridades realistas que Cano Moctezuma se hallaba en comunicación con los insurgentes y que pertenecía a los Guadalupes. ${ }^{36}$

Asentado que la mayor parte de los dirigentes de las parcialidades capitalinas, con excepciones como las ya reseñadas, se solidarizaron con la autoridad virreinal, puede pensarse en otros móviles coadyuvantes en esos testimonios de adhesión:

la militarización general que sufriera el virreinato a partir de entonces [desde 1810] y que tanto afectara a los sectores socio-económicos más bajos de la población vino a despertar en algunos de los funcionarios indígenas, además del deseo natural de evitar que sus gobernados sufrieran las consecuencias de una leva masiva, el deseo de formar con ellos cuerpos organizados que estuvieran bajo su mando y que ofrecieran un apoyo al ejercicio de su autoridad, amenazada por el establecimiento de la Constitución de 1812, que aparentemente abría nuevas vías de acción a los indígenas pero que, de hecho, venía a poner fin a su régimen especial de gobierno. ${ }^{37}$

Las afirmaciones de Virginia Guedea sobre el impacto del texto fundamental de Cádiz en la vida de las comunidades indígenas, que acaban de reproducirse, son contradichas - al menos en parte- por las tesis de Antonio Annino que apuntan a una "interpretación india" de la Constitución, en el sentido de que las parcialidades de la capital supieron defender el "poder étnico", incluso en lo referente a los bienes de comunidad cuya administración se confió a los nuevos ayuntamientos electivos: "entre 1812 y 1813 no era de ningún modo obvio que el traslado de los bienes étnicos a los nuevos cabildos implicara la pérdida automática del control por parte de las dos parcialidades". ${ }^{38}$

35 Anna, Timothy E.: La caída del gobierno español en la ciudad de México, México, 1978, pág. 151 .

36 Prontuario de los insurgentes, págs. 227 y 228, y Lira: Comunidades indígenas..., págs. 55-56.

37 Guedea: “Los indios voluntarios...”, pág. 80.

38 Annino: "Prácticas criollas...", pág. 137. 
El mismo Annino ha enfatizado en otro trabajo la determinación con que se aplicó en la Nueva España el código constitucional de 1812, que no titubeó en la concesión del status de ciudadanía liberal para los indios y que tuvo como consecuencia la entrada de las comunidades en el mundo del constitucionalismo moderno: un ingreso que, sin embargo, implicó la adaptación de las normas políticas de la Modernidad a las tradicionales prácticas de gobierno indígenas, y el consiguiente efecto potencialmente desestabilizador para el nuevo orden. ${ }^{39}$

Andrés Lira relativiza los puntos de vista de Antonio Annino: si bien es cierto que algunos antiguos gobernadores de las parcialidades de la ciudad de México se vincularon a las nuevas instituciones - "para ellos el régimen constitucional era una etapa más en su carrera política"-, las autoridades de las repúblicas dependientes de las parcialidades vieron comprometido su futuro, pues la existencia de ayuntamientos constitucionales señalaba su extinción como focos de poder local. ${ }^{40}$

De otro lado, la matanza de la alhóndiga de Granaditas, en Guanajuato, no sólo aterrorizó a las clases altas y medias de la Nueva España, sino que amedrentó a elementos de inferior condición social, entre los que se contaban numerosos indígenas: "los indios poseedores de tierras comunales y los campesinos sentían temor de ser desposeídos por los pobres carentes de tierras que militaban en las fuerzas de Hidalgo", ${ }^{41}$ como también pudieron experimentar miedo ante la perspectiva de verse enrolados a la fuerza en alguna partida de insurgentes. ${ }^{42}$

Se explica así que poblaciones indígenas, como los habitantes del altiplano central o los empleados de haciendas de las regiones situadas al norte del Bajío, como San Luis Potosí, ${ }^{43}$ prefirieran mantenerse a la expectativa y sólo de modo aislado prestaran apoyo a los insurgentes. Lo mismo ocurrió entre los mixtecos, a quienes debió de resultar poco atractiva la posibilidad de ser gobernados por hombres como los capitanes de Morelos: por eso respondieron con evasivas a las exacciones tributarias y a las demandas de víveres para los cuarteles insurgentes. "Cuando el pueblo de Yodocono resistió un pedido del coronel Aparicio que exigía 25 pesos,

39 Annino: "Nuevas perspectivas...", págs. 54 y 56.

40 Lira: Comunidades indígenas..., pág. 56.

41 Rodríguez O., Jaime E.: La independencia de la América española, México, 1996, pág. 197.

42 Diálogo casero. El aguador, la cocinera y el insurgente. México, 1810, en Rivera, José: Diálogos de la Independencia, México, 1985, págs. $54-57$ (pág. 55).

43 Tutino, John: De la insurrección a la revolución en México. Las bases sociales de la violencia agraria, 1750-1940, México, 1990, págs. 125-146. 
4 arrobas de totoposte y una ración de zacate, la guarnición del cuartel cercano atacó al pueblo con caballería e infantería, quemó los bohíos y se llevó presos a los hombres que lograron atrapar, a quienes el coronel extorsionó por 3.000 pesos antes de soltarlos". ${ }^{44}$

Por lo que hace a los indígenas del valle de México, Timothy E. Anna coincide con Hamill en subrayar la escasa ayuda que proporcionaron a Hidalgo, influidos quizá por la intensa propaganda del gobierno, que divulgó por todos los medios a su alcance los horrores sembrados por la insurgencia en el interior del país. ${ }^{45}$

Es preciso admitir que todavía hoy nos encontramos carentes de información precisa que permita valorar en su justa medida las motivaciones de las regiones y de los diversos grupos sociales que se alzaron en $1810 .{ }^{46}$ Pero el mismo retraso con que se produjo la expedición del decreto por el que Hidalgo obligó a devolver a las comunidades de los naturales las tierras que les habían sido usurpadas ilegalmente - decreto del 5 de diciembre de 1810 - y la limitación del alcance de esa medida, que se circunscribía a la restitución de tierras arrendadas, pueden hacer pensar en un cierto carácter instrumental y en la necesidad en que se veía el cura de Dolores de conciliar los intereses del levantamiento criollo con los de otros sectores sociales que estaban brindando apoyo a la insurrección. La posterior abolición del tributo significó ya un importante paso adelante en la ruptura con el ordenamiento anterior: así lo han entendido Luis Villoro y Enrique Florescano, que interpretan esa medida como expresión de la soberanía efectiva del pueblo y del propósito destructor del orden antiguo. ${ }^{47}$

Tampoco parece imprudente generalizar la hipótesis que formuló William B. Taylor para explicar la incorporación al movimiento insurgente de grupos e individuos de las poblaciones del centro de Jalisco: más que atribuirla a contagio de la propaganda de los rebeldes, habría que pensar en

44 Pastor, Rodolfo: Campesinos y reformas: La mixteca, 1700-1856, México, 1987, págs. $417-$ 418 y 524. Véase también Ortiz Escamilla, Juan: Guerra y gobierno. Los pueblos y la independencia de México, Sevilla, 1997, págs. 130-131.

45 Anna: La caída del gobierno español..., págs. 88-89. Ortiz Escamilla: Guerra y gobierno..., pág. 45. Esa propaganda realista fue secundada por regidores municipales, párrocos y ciudadanos particulares, que se valieron de su influencia sobre las masas para aconsejarles que no se adhirieran a las fuerzas de Hidalgo: Hamill, Jr.: The Hidalgo Revolt..., pág. 175. El mismo Hamill describe las peculiaridades de la propaganda insurgente dirigida a los indígenas, que trataba de acomodarse a su condición de iletrados: "the illiterate Indians and castes had to be won by means of slogans, songs, and banners": ibídem, pág. 127.

46 Van Young: La crisis del orden colonial..., pág. 334.

47 Florescano: Memoria mexicana..., pág. 510. 
el rechazo que provocó la represión realista y su política de tierra quemada. ${ }^{48}$ Del mismo modo resulta convincente su recurso al influjo de los curas sobre sus feligreses, que pudo condicionar de modo decisivo la postura favorable u hostil de éstos hacia la insurgencia. ${ }^{49}$

Los argumentos de que se sirvieron algunos insurgentes para justificar su militancia en el bando contrario al realista se nos antojan, a veces, peregrinos, pero no dejan de remitir a un interesante simbolismo. Van Young recoge la respuesta que dieron unos indios capturados cerca de Yuririapúndaro en 1810, cuando fueron interrogados por su adscripción al campo rebelde: los caciques de sus pueblos les habían ordenado unirse a las fuerzas de Allende por orden del rey. ${ }^{50} \mathrm{Y}$ el mismo autor subraya el extraño entrelazamiento de aspiraciones tan confusas como el mesiánico milenarismo indio y un legitimismo distorsionado, que se concretó en rumores como la presencia de Fernando VII en México, entre 1810 y 1811, disfrazado de un enmascarado que favorecía la causa de los rebeldes. ${ }^{51}$

No cabe duda, desde luego, de que los indígenas que se alzaron en 1810 obedecieron a impulsos que poco o nada tenían que ver con los postulados de la elite protoliberal, y eso aun cuando los símbolos motivadores de su rebeldía fueran formalmente los mismos elegidos por los criollos que dirigían el movimiento. ${ }^{52}$ Lo entendió muy bien Juan de Yandiola, enviado a la Nueva España por las Cortes para analizar la situación del virreinato, cuando advirtió que el movimiento promovido por los criollos se complementaba con otro de raíces populares, que implicaba a muchos indígenas levantados en defensa de su religión y tradiciones, que creyeron amenazadas. ${ }^{53}$

En el curso de los años que duró la contienda, por vez primera, las comunidades indígenas adquirieron conciencia de su propia fuerza, gozaron de una verdadera autonomía, e incluso aprovecharon para adueñarse de tierras o aguas que venían reclamando desde tiempo atrás a propietarios

48 Taylor: "Bandolerismo e insurrección...”, págs. 213 y 219-222.

49 Ibídem, págs. 211 y 216. Francisco Antonio Moreno, cura de San Pedro Quiatoni, obispado de Oaxaca, manifestó por escrito el efecto producido en el pueblo por el paso de un jefe militar insurgente, el presbítero José Antonio Herrero: "fue bien visto y recibido de mis indios, dejándolos desengañados del error que padecían y quedando adictos a la justa causa y defensa de la religión a favor de la nación americana": Prontuario de los insurgentes, págs. 466-467.

50 Van Young: La crisis del orden colonial..., pág. 330.

51 Ibídem, págs. 340, 388, 401-402 y 418-421; Van Young: "Quetzalcóatl, King Ferdinand...", págs. 110-111 y 119-122, y Florescano, Enrique: Memoria mexicana..., págs. 500-503.

52 Van Young: La crisis del orden colonial..., pág. 364.

53 Ortiz Escamilla: Guerra y gobierno..., pág. 39. 
particulares. Esa competencia por la tierra, unida a la tradicional resistencia a las coacciones fiscales, había alimentado desde tiempos remotos frecuentes litigios: y no parece imprudente suponer que, a partir de 1810, influyera en las actitudes favorables a la insurgencia que observamos entre esos pueblos. "Diferencias locales sobre estas cuestiones pudieron determinar que algunas poblaciones se inclinaran a favor de la insurgencia y otras a favor del realismo, o hacia la no participación". ${ }^{54}$

A decir verdad, no todas las rebeliones de indios venían motivadas por pleitos sobre utilización de tierras o de aguas, pero sí se hallaban relacionadas con esta vertiente, de uno u otro modo: por ejemplo, las tensiones provocadas por el endeudamiento, las condiciones de trabajo o la regulación de salarios. ${ }^{55}$ No obstante, como previene Tutino, es preciso limitar el alcance de esas protestas rurales que, en la mayoría de los casos, afectaron sólo a comunidades campesinas aisladas. ${ }^{56}$

El esfuerzo bélico acometido desde 1810 incorporó a muchas de aquellas comunidades, hasta entonces aisladas, a una coalición de intereses cada vez más amplia, pluriétnica y plurisocial: "pueblos indígenas, labradores del campo, pequeños rancheros, mayordomos de haciendas, arrieros, vaqueros, artesanos, letrados provincianos, párrocos, oficiales de la milicia, y aun familias prominentes de la localidad" ${ }^{57}$ En consecuencia, los conflictos locales preexistentes tendieron a ensancharse y su resolución rebasó la disponibilidad de medios con que hacerles frente: por eso, el logro de la independencia política no obtuvo la erradicación de esos problemas. ${ }^{58}$

Aunque la postura más difundida entre los indígenas -incluso antes del grito de Dolores - ${ }^{59}$ fuera favorable a la causa insurgente, algunos de ellos protagonizaran importantes hechos de armas en este bando, muchos sufrieran encierros en calabozos realistas, muchísimos entregaran su vida por la causa de Hidalgo, y otros se distinguieran por los servicios de espionaje y de apoyo desde la retaguardia que prestaron en favor de la insurgencia o por los cuidados que prodigaron a sus heridos y enfermos, resulta

54 Hamnett, Brian R.: Raíces de la insurgencia en México. Historia regional 1750-1824, México, 1990, pág. 46.

55 Ibídem, pág. 48.

56 Tutino: De la insurrección a la revolución..., pág. 48.

57 Hamnett, Brian R.: "Faccionalismo, constitución y poder personal en la política mexicana, 1821-1854: un ensayo interpretativo", en Vázquez, Josefina Zoraida (ed.): La fundación del Estado Mexicano, México, 1994, págs. 75-109 (pág. 77).

58 Hamnett: Raíces de la insurgencia..., pág. 61.

59 Conviene mencionar a este propósito la colaboración que los implicados en la conspiración de Valladolid de 1809 esperaban de los indios: Alamán: Historia de Méjico..., vol. I, págs. 292-293. 
imposible obviar el hecho de que existieron diferencias de opinión en el interior de los pueblos, y que hubo bastantes que lucharon abiertamente en defensa de los derechos esgrimidos por España.

Pocas veces han parado mientes los historiadores en esa presencia de bandos antagónicos en el seno de las comunidades, a que nos referíamos en el anterior párrafo. El hambre de tierras instigó no pocos conflictos internos y condicionó más de una lealtad. Fue el caso, recordado por Ortiz Peralta, de Ixmiquilpan, cuyo gobernador se dirigió en 1812 al Juzgado General de Naturales en solicitud de permiso para una redistribución de las tierras de repartimiento entre nuevos solicitantes, que aprovecharon la coyuntura de que los anteriores beneficiarios se habían sumado a la insurgencia. ${ }^{60}$

Aunque casi toda la provincia de Tlaxcala se hubiera decantado por la causa insurgente, según aseguraba Rayón a Morelos, "el gobernador de indios es del partido contrario, y por razón de su crecido caudal e influjo los tiene en sumo grado oprimidos". ${ }^{11}$ Un indio noble, Diego Páez de Mendoza, capitaneó a los patriotas de Ameca, y derrotó y arrebató el equipaje al insurgente Arroyo cuando huía de Valladolid y trataba de penetrar en la provincia de Puebla. ${ }^{62}$

Otro caso ejemplar fue el de Agustín de la Cruz, gobernador de Yodocono en 1816 y 1818, que fue denunciado como realista por sus convecinos partidarios de la insurgencia. Según la acusación, cuando los rebeldes abandonaron el pueblo, De la Cruz "hizo sacar en procesión el retrato del rey, con música, cohetes y vivas" (lo que no hubiera podido realizarse sin el concurso de mucha más gente) ${ }^{63}$

Recordemos, en fin, a Jorge Cipak, gobernador de Patzún, recomendado por el capitán general de Guatemala al secretario de Estado y Gobernación de Ultramar, para que se le premiara con el derecho a poner las armas reales sobre la puerta de su casa, y para que se le autorizara a nombrar al gobernador de aquel pueblo en la persona de uno de sus hijos: todo ello en recompensa por haber prestado valiosos servicios a la Corona durante la insurrección. ${ }^{64}$

60 Ortiz Peralta, Rina: "Inexistentes por decreto: disposiciones legislativas sobre los pueblos de indios en el siglo XIX. El caso de Hidalgo", en Escobar Ohmstede, Antonio (coord.): Indio, nación y comunidad en el México del siglo XIX, México, 1993, págs. 153-169 (pág. 159).

61 Prontuario de los insurgentes, pág. 392.

62 Alamán: Historia de Méjico..., vol. IV, pág. 27.

63 Pastor: Campesinos y reformas..., pág. 526.

64 AGI, Guatemala, 629. José de Bustamante, presidente y capitán general de Guatemala, al secretario de Estado y de Gobernación de Ultramar, 18 de noviembre de 1814. 
Juan Ortiz Escamilla certifica varios casos de poblaciones cuyos habitantes se dividieron a la hora de decidir a cuál de los dos bandos en pugna iban a apoyar: Tepeji del Río, Chapa de la Mota, Tulancingo. Aunque no se tratara de lugares exclusivamente indígenas, y aunque algunas veces - como en Tulancingo-, la alineación con realistas o insurgentes se identificara con la bipolarización de una sociedad escindida en notables o paisanos honrados y plebe, también es cierto que no hubo unanimidad ni siquiera entre los indígenas. ${ }^{65}$

Por supuesto, la dificultad para asentar juicios de carácter general prevalece también aquí: después de haber registrado varios ejemplos que muestran diversidad de pareceres, no podemos silenciar el caso de la república de Coatepec, de la jurisdicción de Sultepec, que dirigió una representación a Morelos para pedir que les nombrara gobernador. ${ }^{66}$ Difícilmente hubiera prosperado una iniciativa semejante de no existir unanimidad en la adhesión a la insurgencia. Lo mismo parece sugerir la recaudación de cuarenta y siete pesos para la causa rebelde que efectuó la república de Santo Domingo Tonavistla. ${ }^{67}$ No obstante, como en todos los donativos voluntarios, la disposición de los naturales en favor de la insurgencia que insinúa esa colecta ha de ser contemplada con cierta desconfianza, y no implica necesariamente una simpatía generalizada hacia ese bando.

Eric Van Young discrepa de la opinión común que ve en la insurgencia un fenómeno eminentemente mestizo, y se inclina por otorgar carácter mayoritario a la participación indígena en el movimiento insurgente. Sustenta su seguridad en el análisis de una muestra de mil trescientas personas acusadas de pertenecer a aquel bando, que permitió observar que casi el 55\% de los individuos cuya etnicidad pudo ser averiguada eran indígenas, lo cual se "corresponde en grado bastante alto con la conformación étnica de la Nueva España". ${ }^{68}$

No obstante, pensamos que esas observaciones estadísticas, aunque interesantes y meritorias, nada enseñan sobre la postura de los indígenas ante la guerra: en efecto, si la proporción de insurgentes aborígenes descubierta por Van Young equivale a la que guardaba ese sector respecto de la

65 Ortiz Escamilla: Guerra y gobierno..., págs. 107-108.

66 Prontuario de los insurgentes, pág. 447.

67 Ibídem, pág. 501.

68 Van Young, Eric: "Rebelión agraria sin agrarismo: defensa de la comunidad, significado y violencia colectiva en la sociedad rural mexicana de fines de la época colonial", en Escobar Ohmstede: Indio, nación y comunidad..., págs. 31-61 (pág. 54). 
población total del virreinato, no se aporta ningún indicio que permita suponer una predilección de esas etnias por la causa insurgente: simplemente se constata que se reproducía en el campo insurgente la misma estructura poblacional del territorio novohispano.

Se nos ocurren, además, otras objeciones al uso que hace Van Young de la información que recabó para su análisis. Según él mismo declara, la muestra se refiere a "individuos capturados por insurgentes ["como sospechosos de insurgentes", debió escribirse con más propiedad] entre 1810 y $1815 " ;{ }^{69}$ y tal vez no repara en el hecho de que no siempre se demostró que aquéllos a quienes se acusó de participación en la revuelta estuviesen efectivamente comprometidos con ella.

Hubo, por fuerza, casos en que los detenidos resultaron absueltos. Y es bien conocida, por otro lado, la arbitrariedad con que los subdelegados y los comandantes realistas procedían a capturar "insurgentes", para granjearse la estimación de sus superiores y para imponer el terror en las poblaciones que habían manifestado simpatías hacia la causa enemiga. Precisamente de esa ligereza se quejó ante el rey Manuel de la Bodega y Mollinedo, en una representación que firmó en Madrid, el 27 de octubre de 1814: "autorizado cualquiera comandante para calificar de insurgente á el que encuentra en el campo ó poblado, lo hace ordinariamente sin la menor formalidad, y la inmediata ejecucion acaba con la vida de este miembro de la sociedad y decide de la suerte de toda su familia". ${ }^{70}$

Todavía podemos llevar más adelante la crítica a la muestra seleccionada por Van Young de "individuos capturados por insurgentes": no sólo no debe darse por supuesto que todos los acusados fueran insurgentes, sino que aún debe excluirse de esta consideración a muchos que fueron condenados o conceptuados como tales y que, sin embargo, no formaban parte de la insurgencia. ¿O es que la justicia impartida bajo la presión de un ambiente de guerra civil, y sin las garantías establecidas desde 1812 por la Constitución, debe reputarse de infalible?

Si en circunstancias de paz, la inquisición policial y la administración de justicia dejaban tanto que desear, y ofrecían facetas y rigores diversos según fuera la condición socioeconómica de los presuntos trasgresores de la norma, ¿no cabe pensar que eso ocurrió también durante la lucha insurgente? ¿No resultaba más asequible oscurecer las pesquisas policiales y

69 Ibídem.

70 Bodega y Mollinedo, Manuel de la: Representacion hecha al Rey, por el Exmo. Sr. Consejero de Estado Don Manuel de la Bodega y Mollinedo. Méjico, 1820 (LAF 243). 
enmarañar los procesos judiciales en favor de los miembros de las clases acomodadas que de las gentes que carecían de fortuna y que nada podían ofrecer a cambio de su liberación?

Por todo ello, resulta más que verosímil que los depauperados indígenas padecieron el rigor de la represión virreinal más que los criollos y que los mestizos; y que, insurgentes o no, resultaron inculpados con mayor frecuencia que otros grupos étnicos y sociales que gozaban de mayor poder adquisitivo para sobornar a los agentes de la justicia realista.

Para reforzar nuestros argumentos habría que recordar que, a tenor de un bando difundido por Calleja desde Zacatecas, en mayo de 1811, cualquier persona que viajara sin pasaporte corría el riesgo de "ser aprehendid[a] ó tratad[a] como insurjente": si ese débil indicio bastaba a los mandos militares para otorgar el carácter de rebeldes a los que fueran sorprendidos sin esa documentación - y así se registra en los papeles de la época-, no parece que el historiador que escribe a más de siglo y medio de esos acontecimientos pueda conformarse con pruebas tan extremadamente débiles que permitían condenar a muchos inocentes cuyo "pecado" era de ignorancia, y no de insurgencia. ${ }^{71}$

A fin de acabar de ratificar la carencia de bases con que se imputaba a muchos indígenas la condición de insurgentes, resulta pertinente referir un episodio del que dio cuenta Ignacio González Campillo, obispo de Puebla de los Ángeles, a Francisco Xavier Venegas, virrey de la Nueva España. Se quejaba en aquella ocasión el prelado angelopolitano de la torpeza de un tal Manuel Sánchez que, advertido por una denuncia, marchó al frente de su tropa para detener por la noche a unos sospechosos que, según la delación recibida, se disponían a pernoctar en una finca cercana a la capital de la provincia. La inopinada llegada de los soldados asustó al personal de servicio de la hacienda, que dormía plácidamente y pensó que era sorprendido por ladrones. Se trabó un tiroteo, a resultas del cual cayó herido de muerte uno de los criados. Finalizada la refriega, "el Comandante de la expedicion se vino á esta ciudad, ponderó la multitud de Indios, que llamaba insurgentes, y el mucho fuego que se había hecho contra su tropa". ${ }^{22}$

Si Van Young exagera tal vez al sostener que los indígenas se decantaron mayoritariamente por la insurgencia, el juicio de un contemporáneo de la guerra, el obispo electo de Michoacán, Abad y Queipo, peca del otro

71 El Atenéo. Documentos para la historia. Bando de Calleja, t. I. México, 1844 (LAF 390).

72 Condumex, Centro de Estudios de Historia de México, Fondos Virreinales, XI, leg. 95. Ignacio González Campillo a Francisco Xavier Venegas, 19 de octubre de 1811. 
extremo. Así lo anotó Manuel Lorenzo Vidaurre en una glosa a la carta del 20 de junio de 1815 , a través de la cual el prelado asturiano había expuesto su posición ante el fenómeno insurgente: "don Manuel Abad y Queipo con respecto á Méjico, que es la parte de América de que únicamente puede hablar algo, confiesa que los indígenas sensatos é ilustrados fueron opuestos á la independencia, por el sério convencimiento de su espíritu en los inconvenientes que resultaban". ${ }^{73}$

\section{El indígena visto por los caudillos insurgentes}

Incluso si se admite la participación efectiva de muchos indígenas en la insurgencia, y se pondera la voluntad integracionista de Morelos, ${ }^{74}$ resulta incuestionable que también entonces fueron objeto de discriminación por parte de los caudillos militares y de personas acomodadas, que no ocultaban la desconfianza que les inspiraban esas masas levantadas en armas, a las que consideraban incapaces de captar el verdadero sentido de la lucha. Es éste el sentimiento que se trasluce en un comentario bienintencionado de Pedro García, vecino de San Miguel el Grande y uno de los primeros ciudadanos que se unieron a las fuerzas de Hidalgo: "los indígenas daban a conocer su contento cuando llegaron a entender los motivos y fin de aquel movimiento". ${ }^{75}$

Idénticas prevenciones hacia la "plebe" indígena mostraron los Guadalupes en una carta a Morelos, en la que calificaban de "autómatas" a esas gentes, que "no ven mas que lo presente, sin reflexionar en el futuro,

73 Vidaurre, Manuel de: Votos de los Americanos á la Nacion española, y á nuestro amado monarca el Señor Don Fernando VII: verdadero Concordato entre españoles, Europeos, y Americanos, refutando las máximas del obispo presentado Don Manuel de Abad y Queipo en su carta de veinte de junio de mil ochocientos quince. Reimpreso en Méjico, 1820 (LAF 327).

74 Podrían mencionarse a este respecto el bando del 17 de noviembre de 1810, donde Morelos dispuso que ya "no se nombrarán en calidad de indios, mulatos ni otras castas, sino todos generalmente americanos"; su discurso en la apertura del Congreso de Chilpancingo, donde asumió, en nombre del Congreso, la responsabilidad de cambiar "la suerte de seis millones de americanos", o los Sentimientos de la Nación, en los que proscribió la esclavitud y la distinción de castas, "quedando todos iguales, y sólo distinguirá a un americano de otro el vicio y la virtud”: Lemoine, Ernesto: Morelos. Su vida revolucionaria a través de sus escritos y de otros testimonios de la época, México, 1991, págs. 162-163, 367 y 370-373; Legislación indigenista de México, México, 1958, págs. 23-24, y Prontuario de los insurgentes, pág. 80. Véase también Roca, C. Alberto: "De las bulas alejandrinas al nuevo orden político americano", Anuario Mexicano de Historia del Derecho, T. V., México, D. F., 1993, págs. 329-369 (pág. 344).

75 García: Con el cura Hidalgo en la guerra..., pág. 60. Van Young: "Rebelión agraria sin agrarismo...", págs. 49-50. 
y viven conformes con su abatimiento, con que los dexen vivir en los vicios á que cada qual és inclinado". Claro, que esas características negativas podían ser explotadas al servicio de la causa: "ésta clase de gente se dirige segun conviene, y algun partido se podrá sacar de ella". ${ }^{76}$

No otra había sido la preocupación de Ignacio de Allende, que llegó a manifestar a Hidalgo que, puesto que los indios no entendían "el verbo libertad, era necesario hacerles creer que el levantamiento se lleva a cabo únicamente para favorecer al rey Fernando"; ${ }^{77}$ que más de una vez perdió la paciencia con sus seguidores indígenas (en San Miguel y en Guanajuato) $;^{78}$ que, en otra ocasión, se quejó ante el caudillo insurgente de que "los indios están muy alzados" y habían cometido varias atrocidades en las personas de tres europeos y un criollo, ${ }^{79}$ y que, en una carta que escribió a Hidalgo desde Guanajuato, para convencerle de que reuniera sus tropas a las que él mandaba, expuso que el descrédito de los ejércitos insurgentes era tal que "hasta los mismos indios lo han censurado". ${ }^{80}$

Además, persuadir a los indios — como sugería Allende- de que la sublevación se proponía la defensa de los derechos del rey Fernando entrañaba riesgos que desveló José Ignacio Rayón:

supóngase sin embargo, que nuestras armas victoriosas triunfaron por fin de los opresores. Un cálculo ligero y sencillo puede demostrar la debilidad y languidez a que es preciso quedemos reducidos; y entonces la masa enorme de los indios, quietos hasta ahora y unidos con los demás americanos en el concepto de que sólo se trata de reformar el poder arbitrario, sin sustraernos de la dominación de Fernando VII, se fermentará, declarada la independencia y aleccionados en la actual lucha, harán esfuerzos por restituir sus antiguas monarquías, como descaradamente lo pretendieron el año anterior los tlaxcaltecas en su representación al señor Morelo. ${ }^{81}$

Parecidas eran las preocupaciones que Aldama confió al coronel realista Diego García Conde cuando éste se hallaba prisionero en manos de los insurgentes: tanto él como los demás jefes que capitaneaban la insurrección

76 AGI, Indiferente General, 110. Los Guadalupes a Morelos, México, 5 de agosto de 1813, en cuaderno 4, copia de la correspondencia de los Guadalupes, núm. 12 y Serafina Rosier, con Morelos, Matamoros y otros.

77 Citado en Lemoine, Ernesto: “La revolución de independencia, 1808-1821", en Hernández, Octavio (ed.): La República Federal..., vol. IV, t. II, pág. 35.

78 Hamill: The Hidalgo Revolt..., pág. 142.

79 Castillo Ledón: Hidalgo..., vol. II, pág. 105.

80 Bustamante, Carlos María de: Campañas del General D. Félix María Calleja, Comandante en Jefe del Ejército Real de Operaciones, llamado del Centro, México, 1988, pág. 24.

81 Exposición de José Ignacio Rayón al Congreso, en Zavala: Ensayo histórico de las revoluciones..., págs. 299-302 (pág. 301). Alamán: Historia de Méjico..., vol. III, pág. 525. 
se habían persuadido del carácter irrefrenable del movimiento que habían desatado y de que, si los acontecimientos seguían su curso normal, "quedarían estos países en favor de los indios, sus primeros dueños". ${ }^{82}$

Lorenzo de Zavala pareció penetrar en los pensamientos de Allende, cuando escribió: “¿qué podía hacer el coronel Allende, por más conocimientos que se le supongan, con más de cien mil indios que ni entendían el idioma, que mucho menos eran capaces de someterse a la disciplina, y que tenían que entrar en acción inmediatamente?". ${ }^{3}$

En el decisivo trance de marchar sobre la capital del virreinato, desprovista de defensas que pudieran resistir a las fuerzas insurgentes, Allende volvió a manifestar su desconfianza en las hordas de indios, que a duras penas habían triunfado en las Cruces y que, con toda probabilidad, huirían azorados cuando se trabara el combate. ${ }^{84}$

También había sido ése el mensaje que trasladó Carlos María de Bustamante a los españoles de la ciudad de México, cuando intimaba su rendición a las tropas de Morelos: "creisteis que eramos peores que bestias feroces, que no dabamos quartel, y que nuestros exercitos se componian de indios tumultuarios, armados de honda y flecha, por lo que osasteis resistirnos". ${ }^{85}$

Las Campañas del General D. Félix María Calleja, de Carlos María de Bustamante, traslucen el inconsciente menosprecio de su autor hacia los indios. Así, en la descripción de un pequeño enfrentamiento en Puerto Carrozas, en septiembre de 1810, se presenta "á unos miserables indios que ignorando los estragos de la artilleria tapaban las bocas de los cañones con sus sombreros", y en la reseña de la rendición del puerto de San Blas a las tropas realistas, en diciembre del mismo año, se alude a "la impericia y desórden del ejército que lo atacó, compuesto de unos cuantos lanceros y mayor número de indios inexpertos [de dos a tres mil, dirá en otro luga], ${ }^{86}$ que habrian encontrado su ruina si cualquiera de las baterias de la plaza al acometerla les hubiera hecho fuego". ${ }^{87}$

82 Ortiz Escamilla: Guerra y gobierno..., pág. 42.

83 Zavala: Ensayo histórico de las revoluciones..., pág. 48. pág. 90.

84 Castillo Ledón: Hidalgo..., vol. II, pág. 96, y Anna: La caída del gobierno español...,

85 Correo Americano del Sur, núm. XXXIV, 21 de octubre de 1813, en García: Documentos históricos mexicanos..., vol. IV, y García Díaz: "La prensa insurgente...", vol. VI, t. II, págs. 376-377.

86 Bustamante: Campañas..., pág. 75.

87 Ibídem, págs. 21 y 71. 
Cuando el insurgente José Mariano Anaya se presentó en Ixmiquilpan en noviembre de 1810, comisionado por Allende e Hidalgo, transmitió instrucciones escritas a los gobernadores y principales de las repúblicas de indios, para que reunieran a toda su "indiada" y la remitieran a Xochitlán. Las órdenes que impartió dirigidas a los "vecinos de razón" implicaban un tratamiento diferente para éstos, más respetuoso si se quiere con su disponibilidad, pues se limitaban a solicitar que fueran convocado. ${ }^{88}$ Muy parecida fue la conducta de los insurgentes que entraron en Zacatlán a principios de febrero de 1813: enseguida requirieron a los gobernadores de varios pueblos de indios que les suministraran mano de obra que colaborara en los trabajos de fortificación de la ciudad. ${ }^{89}$

El mismo José María Morelos pareció tener bien claro "que nuestro sistema solo se encamina á que el gobierno político y militar que reside en los europeos recaiga en los criollos", y "que siendo los blancos los primeros representantes del reino, y los que primero tomaron las armas en defensa de los naturales de los pueblos y demas castas, uniformándose con ellos, deben ser los blancos por este mérito el objeto de nuestra gratitud y no del odio que se quiere formar contra ellos". ${ }^{90}$ Lógicamente, al interpretar estas palabras del caudillo insurgente, es preciso tomar en cuenta su intencionalidad de captar voluntades para una causa que, sin el apoyo de los criollos, difícilmente podía albergar esperanzas de triunfo.

Por si cabía algún espacio de duda acerca del papel que se reservaba a los criollos - y, por eliminación, a los indígenas - en el nuevo Estado, Morelos remachó en febrero de 1812: "nuestra sentencia no es otra sino que los criollos gobiernen al reino y que los gachupines se vayan a su tierra" ${ }^{91}$ Más contundente aún es el contenido de un Aviso importante al público que, "para que llegue á noticia de todos", hizo circular Morelos desde su cuartel de Aguadulce, en Michoacán, el 10 de agosto de 1814: "corre in voce que por Zacatlán y Chignahuapan les hemos dado un par de golpes á los Mexicanos". ${ }^{92}$

88 Guedea: La insurgencia en el Departamento..., pág. 23.

89 Ibídem, pág. 67.

90 Bando de Morelos, 13 de octubre de 1811, en Lemoine, Ernesto: Morelos..., pág. 182; Dublán, Manuel, y Lozano, José María: Legislación mexicana ó Colección completa de las disposiciones legislativas expedidas desde la independencia de la República, 25 vols., México, 1876-1898, vol. I, núm. 89, págs. 345-346 (13 de octubre de 1811), y Legislación indigenista de México..., págs. 26-27.

91 Primera reconvención dirigida por Morelos, desde Cuautla, a los criollos que militan en las filas realistas, 23 de febrero de 1812, en Lemoine: Morelos..., pág. 195.

92 Ibídem, pág. 478. Aviso importante al público. 
En cambio, aunque el bando que Morelos tituló Contra Plan de Calleja, del 7 de julio de 1813, incluya una clasificación de los habitantes del reino en cuatro clases, y enumere las obligaciones propias de cada una de ellas, no puede ser interpretado como si se tratara de una marcha atrás en el camino hacia la supresión de distingos: fueron consideraciones estrictamente militares las que sirvieron para esa catalogación de las personas, según su disponibilidad para el servicio de las armas. ${ }^{93}$

También es cierto que José María Morelos predicó la libertad para el Anáhuac, y prometió "restablecer el Imperio Mexicano" mediante los trabajos de la asamblea que se instaló en Chilpancingo. De ahí su mítica invocación a los "genios de Moctezuma, Cacama, Quautimozin, Xicotencal y Calcontzin", emplazados a contemplar

el fausto momento en que vuestros ilustres hijos se han congregado para vengar vuestros ultrajes y desafueros y librarse de las garras de la tiranía y fanatismo que los iba a sorber para siempre. Al 12 de agosto de 1521 sucedió el 14 de septiembre de 1813; en aquél se apretaron las cadenas de nuestra servidumbre en México-Tenoctitlan; en éste se rompen para siempre en el venturoso pueblo de Chilpancingo. ${ }^{94}$

Con todo, el recurso a ese simbolismo - perfectamente comprensible desde una perspectiva de indagación en las propias raíces- no comportaba ni remotamente, en el ánimo de Morelos, una especial consideración del mundo indígena en el proyecto del nuevo Estado.

\section{A modo de conclusión}

Con las limitaciones que se quiera, y aun admitiendo la supeditación de las comunidades indígenas a los proyectos políticos de los dirigentes de la insurgencia, permanece el hecho de que la guerra atrajo sobre ellos destrucción y, en muchos casos, abandono de sus pueblos: un estado de cosas que a mediados de siglo distaba de haberse resuelto. Así, los campesinos de Cuyutlán, Santa Fe, San Diego y San Juan Bautista solicitaron al Congreso de Jalisco, en 1849, la devolución de las tierras de asiento de sus pueblos, que habían debido abandonar a consecuencia de la guerra, entre 1810 y

93 AGI, Guatemala, 531. Bando de Morelos Contra Plan de Calleja, 7 de julio de 1813, anexo a una carta del gobernador de Chiapas, 20 de octubre de 1813. Véase Lemoine: Morelos..., págs. 331-335.

94 Ibídem, Discurso pronunciado por Morelos en la apertura del Congreso de Chilpancingo, 14 de septiembre de 1813, págs. 365-369 (pág. 369). 
1811. Ni que decir tiene que la resolución de la legislatura estatal no consideró de utilidad pública la restitución de los terrenos, y recomendó el camino de los tribunales de justicia para una eventual demanda contra las personas que se habían establecido allí..$^{95}$

Aunque el caso referido en el párrafo anterior revista un aspecto muy particular, que no cabe generalizar, existen abundantes elementos de juicio que inducen a pensar que el sacrificio realizado por muchos indígenas durante las guerras insurgentes fue baldío o, al menos, aprovechó a otros. Los aborígenes mexicanos podían identificarse, en líneas generales, con las palabras de un personaje de La coqueta:

¿para qué he ido a exponer mi vida en los campos de batalla? ¿para qué la exponen tantos valientes agrupados en derredor del estandarte de la libertad? ¡Libertad! ¿Y para quién es la libertad? ¿Pueden ser libres instantáneamente esos millones que tenemos de seres degradados, cuando no sienten en sí mismos la dignidad de hombres? ¿Para qué es la igualdad, si no podrían soportarla en parte alguna?96

Por mucho que se escribiera en los días de la guerra y en fechas muy posteriores, persistió la discriminación de los indígenas, incluso por parte de los caudillos insurgentes que se beneficiaron del generoso esfuerzo desplegado por muchos de ellos. Pero se intentó silenciar ese hecho, al tiempo que se magnificaba y se mitificaba la aportación indígena al movimiento liberador.

En efecto, y como destacó oportunamente Doris Ladd, las historias sociales del período de la insurgencia tienden a enmascarar el papel relevante que jugaron entonces las clases adineradas, y prefieren centrar su atención en los grupos oprimidos — campesinos, negros, indígenas-, "dada la propensión a buscar el significado del pasado histórico en la 'cultura de la pobreza"., ${ }^{97}$

Mariano Otero, que no necesitaba manipular la aportación de los postergados a la lucha emancipadora, valoró de manera muy diferente el papel de los privilegiados criollos, y se refirió en términos entusiásticos a la acción de la "raza trasplantada", llamada por Dios para quebrantar "las cadenas de aquellos pueblos que con solícito cuidado había hecho crecer en los ignorados bosques del Nuevo Mundo", y aprestándose a proclamar "la igualdad de todos los derechos y de todas las obligaciones, extinguiendo las pág. 76.

95 Reina, Leticia (coord.): Las luchas populares en México en el siglo XIX, México, 1983,

96 Pizarro, Nicolás: La coqueta, Méjico, 1861, pág. 18.

97 Ladd, Doris: La nobleza mexicana en la época de la independencia 1780-1826, México, 1984, pág. 19. 
distinciones absurdas y funestas, que han dividido a los pueblos en dos razas, la una de señores y la otra de esclavos". ${ }^{98}$

No difería en mucho el pensamiento de Ignacio M. Altamirano, que no tuvo recato en aceptar que "el elemento social a cuyo impulso se consumó la independencia de la Patria no fué ni el indigenato mexicano ni el elemento popular compuesto de las clases que hacían causa común con él", pues lo impedían "sus intereses y su alejamiento de las cosas públicas": hasta tal punto que, de haber triunfado la revolución de 1810, las clases privilegiadas habrían sido barridas por quienes consideraban ya insufribles sus abusos. ${ }^{99}$

Los primeros caudillos de la causa emancipadora procedían, según Altamirano, de las capas bajas de los criollos, las de condición menos favorecida, las

castas mestizas que los españoles llamaban con desdén criollas para distinguirlas de los habitantes de la colonia de origen español, y aun de una cierta clase aristocrática formada aquí después de la conquista y que había adquirido altos fueros y privilegios y aun títulos de nobleza, sea a causa de sus riquezas territoriales o mineras, sea por enlaces contraídos en España o por el simple favoritismo. ${ }^{100}$

Maqueo Castellano, que conceptuó la insurrección de 1810 como un "relámpago de iracundia, de los oprimidos contra los opresores", afirmó categóricamente: "nadie podrá nunca probar que fué el indio el que hizo la independencia de la Patria, por más que hayan sido indios muchos de sus gloriosos caudillos, aunque los más eran criollos"; ${ }^{101}$ y eso, porque la mayoría de aquellas razas "vencidas, vilipendiadas, muertas" respondieron con la indiferencia a la llamada que se les dirigió para que se sumaran a la rebeldía. Pero, aun cuando se admitiera que "la gran masa indígena" se levantó en armas, nunca se podría sostener que alcanzara a comprender los móviles de la sublevación. A lo sumo, "el indio pudo acaso ver en la Independencia tres cosas: el recobro de las tierras, la liberación del pago de impuestos y de la prestación de servicios personales, y la ruina del español que se había hecho odiar". ${ }^{102}$

98 Otero, Mariano: Obras, recopilación, selección, comentarios y estudio preliminar de Jesús Reyes Heroles, 2 vols., México, 1967, vol. II, págs. 469 y 470.

99 Altamirano, Ignacio M.: Historia y política de México (1821-1882), México, 1947, páginas 19 y 26.

100 Ibídem, pág. 19.

101 Maqueo Castellanos, E.: Algunos problemas nacionales, México, 1910, pág. 76.

102 Ibídem, pág. 77. 